\title{
AMAMENTAÇÃO EM CRECHES NO BRASIL
}

\author{
BREASTFEEDING IN BRAZILIAN CHILD \\ DAY CARE CENTERS
}

\author{
Natália Pinheiro Braga ${ }^{1}$ \\ Magda Andrade Rezende ${ }^{2}$ \\ Elizabeth Fujimori ${ }^{3}$
}

Braga NP; Rezende MA; Fugimori E. Amamentação em creches no Brasil. Rev Bras Crescimento Desenvolv Hum. 2009; 19(3): 465-474.

\section{Resumo:}

Amamentação até dois anos depende de condições ambientais (proximidade física entre mãe/lactente, administração de leite ordenhado) que podem ser favorecidas por creches. Assim, o objetivo deste estudo foi avaliar como as condições estruturais e as rotinas de acolhimento são abordadas em estudos que tratam da relação amamentação-creche. Fez-se revisão de literatura nas bases de dados LILACS e SCIELO, sem limite de tempo, e na MEDLINE, de 1966 a 2008. Foram selecionados 9 trabalhos. Poucos estudos abordam as condições estruturais (existência de sala ou local adaptado para amamentação, poltrona ou cadeira com braços para as mães amamentarem, água, sabão e toalha para uso das mães, local para extração e armazenamento do leite materno com geladeira e/ou congelador doméstico, potes de vidro, etiquetas e mesas auxiliares). Também são pouco abordadas as rotinas de acolhimento (incentivo das creches para que as mães amamentem por livre demanda, incentivo das creches para extração, armazenamento e administração de leite ordenhado ao bebê). Creches com ambiente e rotinas que favoreçam a amamentação são imprescindíveis. O tema deve ser pesquisado pela comunidade científica e promovido pela sociedade civil.

Palavras-chave: aleitamento; saúde da criança; creches; promoção da saúde; enfermagem pediátrica.

1 Graduanda em Enfermagem pela Escola de Enfermagem da USP (Universidade de São Paulo, capital), bolsista do Programa Institucional de Bolsas de Iniciação Científica USP, número 081.273.7.3. Membro do grupo de pesquisas "Cuidado à Saúde Infantil”. naty-braga@hotmail.com

2 Enfermeira. Livre-docente, Professora Associada da Escola de Enfermagem da USP (capital) no Departamento de Enfermagem Materno-infantil e Psiquiátrica. Fundadora e coordenadora do grupo de pesquisas "Cuidado à Saúde Infantil”.

Endereço para correspondência: Av. Dr. Enéas Carvalho Aguiar 419. São Paulo (capital). CEP 05403-000. marezend@usp.br

3 Livre-docente, Professora Associada da Escola de Enfermagem da USP (capital) no Departamento de Enfermagem em Saúde Coletiva. Líder do Núcleo de Estudos Epidemiológicos na Perspectiva da Enfermagem em Saúde Coletiva. 


\begin{abstract}
The breastfeeding process up to the age of two years depends on environmental conditions (mother/infant physical proximity, milk management) which can be favored by the child day care centers. Thus, the aim of this study was to evaluate how structural conditions and care routine are approached in studies reporting breastfeeding/child day care center relationship. A review of the literature was carried out on LILACS and SCIELO databases, without time limit and, in the MEDLINE, from 1966 to 2008. Nine studies were selected. Few studies approached structural conditions (whether there is a room or an adequate place for breastfeeding, armchair or chair with support for the mother to breastfeed, water, spoon and towel for mothers, a place to extract and storage maternal milk with refrigerator and/ or domestic freezer, glass pots, tags and support tables). Also, were rarely found care routines (incentive of child day care centers to motivate mother to breastfeed on demand, incentive for milk extraction, storage and baby milk management). Child day care centers with an adequate environment and routines favoring breastfeeding are essential. This is an important issue to be investigated by the scientific community and promoted by the society.
\end{abstract}

Key words: breast feeding; child health; child day care centers; health promotion; pediatric nursing

\section{INTRODUÇÃO}

Considerado um alimento completo, o leite materno deve constituir a única fonte de hidratação e alimentação nos primeiros seis meses de vida. A partir do sexto mês, outros alimentos devem ser introduzidos gradualmente, mas o aleitamento materno deve continuar até os dois anos de idade ou mais. ${ }^{1}$

Apesar dos esforços empreendidos nos últimos anos, as taxas brasileiras de aleitamento materno exclusivo e total continuam muito baixas em relação às recomendações, 2,2 e 7,6 meses respectivamente, segundo dados da última Pesquisa Nacional de Demografia e Saúde da Criança e da Mulher. ${ }^{2}$ A amamentação depende intensamente de condições ambientais, dentre estas, a necessidade da proximidade física entre mãe e lactente. Nesse sentido, as creches, instituições de educação e de cuidado que atendem crianças menores de três anos de idade em regime de semi-internato podem favorecer muito a amamentação. ${ }^{3,4}$

No Brasil, estima-se que cerca de 970.000 crianças possam ser potencialmente beneficiadas com a promoção do aleitamento materno em creches, o que representa $15,5 \%$ dos menores de dois anos que frequentam esse tipo de instituição ${ }^{5}$, a maioria com permanência por 4 a 10 horas por dia. ${ }^{6}$ Há que se considerar também as trabalhadoras informais, que não tem licença maternidade, e necessitam retornar ao trabalho logo após o parto. Assim é comum encontrar em creches bebês com um mês de vida que já recebem leite em mamadeira, pois o porcentual de trabalhadoras com carteira de trabalho assinada não atingia $40 \%$ em 2008. ${ }^{7}$

Para se promover a amamentação considerou-se a necessidade de que as creches disponham de condições estruturais e rotinas de acolhimento. Essas duas categorias foram criadas com base em estudo que avaliou a amamentação em creche governamental. ${ }^{4}$ As condições estruturais consistem na existência de local ou sala para amamentação, poltrona ou cadeira com braço onde as mães possam se sentar para amamentar, água, sabão e toalha para uso das mães, bem como local para extração e armazenamento do leite materno. As ro- 
tinas de acolhimento, por sua vez, dizem respeito a condutas sistematizadas de incentivo para que a nutriz entre na creche sempre que necessário para amamentar e/ou seja orientada a extrair e guardar seu leite para ser administrado ao bebê posteriormente.

Tais condições são tão importantes que a Consolidação das Leis do Trabalho (CLT) ${ }^{8}$, já em 1943, preconizava a existência de sala de amamentação nos locais em que trabalhassem mais de 30 mulheres com 16 anos idade ou mais. Do mesmo modo, a sala de amamentação é recomendada nas "Normas para construção e instalação de creches”, devendo ter sua área calculada de acordo com o número de crianças de 3 meses a 1 ano, possuir lavatório e ser de fácil acesso. ${ }^{9}$ De acordo com essa norma, para cálculo do espaço deve-se prever " $1,20 \mathrm{~m}^{2}$ por criança do grupo A [de zero a um ano de idade], em fase de amamentação. Considerando-se para sua utilização o revezamento das mães que amamentam, a sala deve possuir área capaz de atender a 30\% do total de crianças desse grupo etário”.

Quanto à extração e guarda de leite materno, dispõe-se de normas brasileiras publicadas pela Fundação Oswaldo Cruz (FIOCRUZ) $^{10,11}$ e pela Agência Nacional de Vigilância Sanitária (ANVISA) ${ }^{12}$ que podem ser usadas em creches.

Considerando a pertinência e importância desse assunto na promoção do aleitamento materno, buscou-se avaliar como as condições estruturais e as rotinas de acolhimento têm sido abordadas nos estudos que tratam da relação amamentação-creche.

\section{MÉTODO}

Fez-se revisão de literatura nas bases de dados Literatura Latino-americana e do Caribe em Ciências da Saúde (LILACS) e Scientific Electronic Library Online (SCIELO), sem limite de tempo, e na Medical
Literature Analysis and Retrieved System (MEDLINE), no período de 1966 a 2008. Usou-se os descritores catalogados no DECs e no MESH: "aleitamento materno", "berçários", "creches”, e "amamentação" em diferentes combinações. A busca bibliográfica foi realizada em setembro de 2008.

Inicialmente, realizou-se leitura exploratória dos títulos e resumos que permitiu obter uma visão global do material e sua pertinência à pesquisa em questão. Para a seleção das produções, utilizou-se como critério de inclusão, ser pesquisa a respeito da realidade brasileira acerca da relação amamentação-creche.

Para a coleta de dados, utilizou-se instrumento com as seguintes informações: autor, ano de publicação, local de realização da pesquisa, objetivos, participantes, tipo de metodologia usada, bem como condições estruturais e rotinas de acolhimento relacionadas à amamentação, categorias de análise criadas para esta pesquisa.

\section{RESULTADOS}

Foram encontrados 85 estudos, mas apenas 8 preenchiam o critério de inclusão. Uma dissertação, que ainda não constava nas bases de dados por ser recente, foi incorporada ao material de análise. ${ }^{13}$ Assim, obteve-se 6 artigos e 3 dissertações apresentados resumidamente no Quadro da página seguinte.

Os estudos encontrados foram publicados entre 1992 e 2008 e desenvolvidos nas regiões Sudeste e Sul do Brasil. Três eram de natureza qualitativa ${ }^{13-15}$, os outros quantitativos. ${ }^{4,16-20}$ Do total de autores $(n=28)$, a maioria vinculava-se a instituições de ensino superior $(\mathrm{n}=19)$, seguido por governamentais $(\mathrm{n}=9)$ e privadas $(\mathrm{n}=1)$. Os métodos usados para a coleta dos dados foram: questionário estruturado ou semiestruturado $(n=6)$, entrevista individual $(n=3)$, entrevista familiar 
Figura 1: Aleitamento materno em creches brasileiras, de acordo com as condições estruturais e rotinas de acolhimento

Autor, ano da publicação,
local da realização da
pesquisa, número de creches
estudadas

\begin{tabular}{lll}
\hline Rezende (1992). & $\begin{array}{l}\text { Quantitativo e } \\
\text { emparelhado.Questionários } \\
\text { aplicados a mães diferentes em }\end{array}$ & $\begin{array}{l}172 \text { mães de crianças de 0 a 1 } \\
\text { ano que frequentavam a creche } \\
\text { em estudo. Ao todo, }\end{array}$ \\
$\begin{array}{ll}1 \text { creche de hospital escola } \\
\text { público, São Paulo (SP) }\end{array}$ & $\begin{array}{l}\text { participaram 85 mães em } 1989 \\
\text { e 87 em } 1991 .\end{array}$
\end{tabular}

Issler et al. (1994).
1 creche
no local de trabalho materno e
creches fora do trabalho, Três
Coroas e Parobé (RS)

Rea et al. (1997)

.4 creches no local de trabalho materno, 3 creches fora do local de trabalho, sendo uma com banco de leite. São Paulo (SP)

Quantitativo e transversal.
Questionários aplicados às mães.Coleta realizada em 1992. 137 mães de lactentes de 0 a 35,9 meses. 65 de lactentes de creche no local de trabalho e 72 de lactentes de creche fora do local de trabalho. $1^{\text {a }}$ fase: 76 gestantes no terceiro trimestre de gestação. $2^{\mathrm{a}}$. fase: 69 mães (as mesmas da fase anterior) no retorno ao das questões fechadas. Na $2^{\mathrm{a}}$. fase: perguntas semiestruturadas.Coleta realizada trabalho. em 1994.

\begin{tabular}{|c|c|c|c|}
\hline $\begin{array}{l}\text { Santos-Oliveira, Rabinovitch } \\
\text { (1999).1 creche no local de } \\
\text { trabalho materno. São Paulo } \\
\text { (SP). }\end{array}$ & $\begin{array}{l}\text { Qualitativa (etoetnográfico). } \\
\text { Combinação de técnicas: } \\
\text { entrevista individual e familiar, } \\
\text { observação, filmagem. Coletas } \\
\text { realizadas provavelmente em } \\
\text { 1992, } 1994 \text { e } 1996 .\end{array}$ & $\begin{array}{l}\text { Mães de } 257 \text { crianças de } 4 \text { a } 12 \\
\text { meses, que frequentavam } \\
\text { creche no local de trabalho } \\
\text { (cidade de São Paulo). }\end{array}$ & $\begin{array}{l}\text { Condições estruturais: havia uma sala de } \\
\text { amamentação. } \\
\text { Rotinas de acolhimento: as mães podiam } \\
\text { entrar na creche para amamentar em } \\
\text { horários pré-determinados. }\end{array}$ \\
\hline $\begin{array}{l}\text { Spinelli et al. (2002).12 creches } \\
\text { públicas municipais da região } \\
\text { de Freguesia do Ó, cidade de } \\
\text { São Paulo (SP) }\end{array}$ & $\begin{array}{l}\text { Quantitativo e transversal. } \\
\text { Aplicados questionários com a } \\
\text { maior parte das questões } \\
\text { fechadas. Coleta realizada em } \\
2000 .\end{array}$ & $\begin{array}{l}\text { Mães de } 235 \text { crianças menores } \\
\text { de } 18 \text { meses. }\end{array}$ & $\begin{array}{l}\text { Condições estruturais: não há relato. } \\
\text { Rotinas de acolhimento: as mães podiam } \\
\text { entrar na creche para amamentar. }\end{array}$ \\
\hline $\begin{array}{l}\text { Uchimura et al. (2003).2 } \\
\text { creches públicas, Maringá (PR) }\end{array}$ & $\begin{array}{l}\text { Quantitativo e } \\
\text { transversal.Aplicados } \\
\text { questionários às mães. Coleta de } \\
\text { dados em } 2001 .\end{array}$ & $\begin{array}{l}126 \text { mães de crianças que } \\
\text { frequentavam as creches. }\end{array}$ & $\begin{array}{l}\text { Condições estruturais: não há relato. } \\
\text { Rotinas de acolhimento: não há relato. }\end{array}$ \\
\hline $\begin{array}{l}\text { Osis et al. (2004).1 creche no } \\
\text { local de trabalho materno, } \\
\text { Campinas (SP) }\end{array}$ & $\begin{array}{l}\text { Qualitativo e longitudinal. } \\
\text { Selecionada amostra proposital } \\
\text { para entrevista semiestruturada. } \\
\text { Após, realizados grupos focais. }\end{array}$ & $\begin{array}{l}15 \text { mães de bebês aleitados } \\
\text { exclusivamente ao começar a } \\
\text { frequentar creche e } 15 \text { mães de } \\
\text { bebês em aleitamento misto ao } \\
\text { começar creche. }\end{array}$ & $\begin{array}{l}\text { Condições estruturais: não há relato. } \\
\text { Rotinas de acolhimento: não há relato. }\end{array}$ \\
\hline $\begin{array}{l}\text { Santos (2006). } \\
12 \text { creches no local de trabalho } \\
\text { materno, Região metropolitana } \\
\text { de São Paulo (SP) } \\
\text { Maciel (2008). }\end{array}$ & $\begin{array}{l}\text { Quantitativo, descritivo e } \\
\text { transversal. Amostra de } \\
\text { conveniência, com uso de } \\
\text { questionário estruturado e } \\
\text { autoaplicado pelas mães.Coleta } \\
\text { de dados: } 2005 \text { a } 2006 . \\
\text { Qualitativo e transversal. }\end{array}$ & $\begin{array}{l}12 \text { creches de empresas } \\
\text { privadas. } 105 \text { mães de crianças } \\
\text { de } 6 \text { a } 12 \text { meses que } \\
\text { frequentavam tais creches. }\end{array}$ & $\begin{array}{l}\text { Condições estruturais: não há relato. } \\
\text { Rotinas de acolhimento: não há relato. } \\
\text { Era possível extrair o leite durante a } \\
\text { jornada de trabalho, mas não é possível } \\
\text { identificar se em creche ou local de } \\
\text { trabalho. }\end{array}$ \\
\hline $\begin{array}{l}1 \text { creche de hospital escola da } \\
\text { cidade de São Paulo (SP) }\end{array}$ & & $\begin{array}{l}10 \text { trabalhadores (7 educadoras, } \\
1 \text { auxiliar de enfermagem, } 1 \\
\text { auxiliar administrativo e a } \\
\text { diretora) que atuaram em } \\
\text { aleitamento materno na creche, } \\
\text { com crianças menores de } 1 \text { ano } \\
\text { entre } 2003 \text { e } 2007 \text {. }\end{array}$ & $\begin{array}{l}\text { Condições estruturais: não há relato. } \\
\text { Rotinas de acolhimento: as mães podiam } \\
\text { entrar na creche para amamentar. }\end{array}$ \\
\hline
\end{tabular}
Condições estruturais: não há relato. Rotinas de acolhimento: não há relato. Condições estruturais: havia banco de leite em uma das empresas estudadas. Nada relatado quanto às creches. Rotinas de acolhimento: havia possibilidade de extração e guarda do leite materno no banco de leite, localizado em uma das
empresas. Nada relatado quanto às creches. Condições estruturais: havia uma sala de amamentação. entrar na creche para amamentar em Condições estruturais: não há relato. Rotinas de acolhimento: as mães podiam

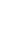

Condições estruturais e rotinas de acolhimento das creches estudadas

Condições estruturais: Existiam duas salas de amamentação com poltronas, pia, água, e sabão.Rotinas de acolhimento: mães amamentavam por livre demanda, combinavam quando iriam fazê-lo ou eram chamadas por telefone, quando o bebê sentia fome. Além disto, as mães podiam realizar extração de leite na creche.

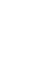


$(n=1)$, grupo focal $(n=1)$, observação $(n=1)$ e filmagem $(n=1)$. Dois trabalhos empregaram mais de um método. ${ }^{14,15}$

Ao todo, 41 creches foram estudadas nos 9 trabalhos analisados. Não é possível dizer, quantas, destas 41, tinham algum tipo de ação de promoção ou apoio ao aleitamento materno, uma vez que os trabalhos realizados com várias creches ${ }^{16-20}$ não deixam claro quantas efetivamente as realizavam. Entende-se como ação de promoção ou apoio: local específico para que a mãe amamentasse, rotina de funcionamento que possibilitasse ou incentivasse a mãe a ir à creche para amamentar ou extrair e armazenar seu leite para ser administrado ao bebê mais tarde.

Os estudos, mesmo os que defendiam a importância da creche como local de promoção e apoio ao aleitamento, pouco apresentaram em termos de descrição das condições estruturais e rotinas, que efetivamente demonstrassem que o aleitamento acontecia. Foi comum ter-se obtido a informação por indícios, como, por exemplo, "havia uma sala de amamentação"14, "local e horários especiais" que não eram especificados. ${ }^{18}$ Somente um dos trabalhos descreveu atendimento que abrangia vários tópicos das duas categorias de análise (condições estruturais e rotinas de acolhimento). ${ }^{4}$ A creche em questão era mantida em grande hospital-escola público da cidade de São Paulo que facilitava o aleitamento através de condições estruturais e rotinas específicas: duas salas de amamentação; cadeiras com apoio para os braços; pias; horário de amamentação flexível, estabelecido em comum acordo entre nutriz e educadora, além do costume da educadora chamar as mães por telefone para amamentar, caso o bebê chorasse fora do horário combinado. Também era possível a extração e armazenamento de leite.

No entanto, apesar deste ter sido o único trabalho no qual se reportam tantas condições, é preciso considerar que outras creches estudadas podiam ter condições favoráveis que não foram descritas, em que pese a estranheza que este fato causa, em se tratando de trabalhos a respeito da relação amamentação-creche.

A seguir apresentamos os resultados de acordo com as categorias de análise. Ressalta-se novamente que a maior parte dos estudos não apresenta com clareza informações a respeito das condições e rotinas necessárias para o aleitamento. Portanto, as informações serão apresentadas com ressalvas, quando necessário.

\section{Condições estruturais favorecedoras da amamentação}

No que diz respeito a tais condições obteve-se o seguinte: sala ou local para amamentação foi mencionada claramente em dois trabalhos $^{4,14}$. Em outros cinco entende-se que devia existir, mas tal informação não foi explicitada ${ }^{15-18,20}$. Cumpre salientar que quatro destes trabalhos analisaram a situação de múltiplas creches, portanto potencializando a possibilidade de haver número maior de salas ou locais para amamentação ${ }^{16-18,20}$.

Poltrona ou cadeira de braços para a mãe sentar-se confortavelmente ao amamentar foi mencionada apenas em um estudo ${ }^{4}$, aliás, o único que fez referência à disponibilidade de água, sabão e toalha para a higiene da nutriz.

Nenhum dos trabalhos mencionou outras condições tão importantes quanto as anteriores e que são local e material para extração e armazenamento do leite materno (geladeira e/ou congelador, frascos de vidros, etiquetas, mesinhas auxiliares, balcão, etc).

Há menção à existência de postos de coleta e guarda de leite humano nos locais de trabalho maternos ${ }^{17,20}$, outra importante modalidade de apoio ao aleitamento, mas que foge ao propósito deste trabalho. 


\section{Rotinas de acolhimento favorecedoras da amamentação}

Possibilitar o livre acesso materno à creche, tanto para amamentar, quanto para extrair e armazenar o leite foi rotina identificada apenas em um trabalho ${ }^{4}$. Outros dão a entender que a nutriz podia entrar, mas não se tem clareza a respeito do modo e da periodicidade com que isto acontecia ${ }^{13,15-17,20}$. Um dos trabalhos dizia que os "horários [eram] pré-determinados” ${ }^{14}$, mas não se sabe quem os determinava, nem como. Outro afirmava que as creches criavam "condições e horários especiais" ${ }^{18}$, mas também não se sabe quem criava estes horários e condições.

Possibilitar a extração do leite materno na creche foi mencionado apenas em um trabalho, realizado em uma creche de hospital escola ${ }^{4}$. Guardar o leite extraído, bem como administrá-lo ao bebê não foi mencionado por trabalho algum realizado em creche. Houve apenas dois estudos ${ }^{17,20}$, num dos quais se pesquisou 13 empresas da cidade de São Paulo, das quais 4 tinham creche no local de trabalho ${ }^{17}$. Nenhuma destas creches tinha posto de coleta de leite. O local de trabalho é que tinha, e foi avaliado que isto trazia benefícios aumentando o tempo de aleitamento materno exclusivo em 19 dias. O segundo estudo ${ }^{20}$, cujos dados foram obtidos junto a 12 empresas localizadas em quatro municípios da região metropolitana de São Paulo, menciona que 10,7\% das 105 mães entrevistadas extraíam leite durante a jornada de trabalho, sem especificar localização ou qualquer outra informação acerca das instituições.

\section{Influência da creche no aleitamento materno}

No que diz respeito a creches no local de trabalho, é possível perceber que esta pode ser associada à maior duração do aleitamento materno. Quatro estudos permitem esta conclusão, dois realizados em instituições de ensino públicas ${ }^{4,15}$ e dois ligados a instituições privadas $^{16,17}$.

No estudo realizado em creche de hospital escola público, localizado na cidade de São Paulo4, 134 das 172 crianças (77,91\%) cujas mães foram entrevistadas eram ou tinham sido amamentadas na creche em algum momento. Destas, 105 (80,15\%) eram amamentadas na creche em média 2 a 3 vezes por dia. Doze crianças $(9,16 \%)$ eram amamentadas diariamente 4 vezes ou mais. Estas cifras demonstram um resultado muito importante baseado apenas no livre acesso materno combinado à existência de local apropriado para amamentação. Sem dúvida é importante lembrar que, por se tratar de uma instituição pública, também pode ter havido influência da política de estabilidade de emprego. Esta análise é reforçada por estudo realizado em creche de uma instituição privada, localizada na cidade de São Paulo. Nesta pesquisa qualitativa as nutrizes relataram o intenso desconforto que sentem devido a comentários depreciativos de colegas e superiores quando necessitam amamentar (segundo informação da Profa.Dra. Damaris Gomes Maranhão, ao relatar pesquisa em vias de publicação).

Também houve ligação entre creche no local de trabalho materno e manutenção do aleitamento, especialmente o exclusivo, após o término da licença maternidade, realizada em universidade pública na cidade de Campinas ${ }^{15}$. Nesta pesquisa foi explorada a situação de uma das creches da mencionada universidade.

Os estudos realizados em instituições privadas apontaram na mesma direção. O realizado em creches gaúchas pesquisou as localizadas no local trabalho materno, bem como outras, externas a este. Constatou-se que as no local de trabalho favorecem amamentação superior a três meses significativamente $\left(\mathrm{X}^{2}=18,65, \mathrm{p}=0,00001\right) .{ }^{16}$ Creche fora do local de trabalho implicou em 
risco quase 3 vezes maior $(2,89)$ de desmame antes do $3^{\circ}$ mês.

Pesquisa realizada na cidade de São Paulo, em creches localizadas em indústrias (local de trabalho materno), bem como outras externas a este ${ }^{17}$, permitiu descobrir que as primeiras estão associados a mediana de aleitamento maior (31 dias) do que nas demais (12 dias). Estes resultados nos levam a acreditar que estas mães, que, aliás, foram entrevistadas em dois momentos, enquanto gestantes e após o retorno ao trabalho, devem ter se organizado de acordo com as condições que seu trabalho oferecia. As medianas de aleitamento predominante e misto reforçam isto, pois apresentaram consistentemente números maiores no que diz respeito às creches no local de trabalho.

Quanto aos outros estudos as evidências são insuficientes para fazermos este tipo de análise.

\section{DISCUSSÃO}

Constata-se que a maior parte das pesquisas destinadas a conhecer como se dava a amamentação em creches, e se esta teria algum efeito positivo no incentivo à amamentação, em geral se pautou apenas no segundo destes dois tópicos. Além disto, as pesquisas mantiveram seu foco em aspectos muito similares, como por exemplo, a associação entre aleitamento materno e fatores como escolaridade materna, sexo do bebê, e peso ao nascer. Isto é, pouco foi explorado acerca do modo de organização interno da instituição creche com vistas a promover o aleitamento, como se o amamentar se desse naturalmente, sem necessidade de organização. Por consequência, pouco é abordado a respeito do contexto em que amamentação acontece, ou melhor, do que é necessário para que ela ocorra.

Vale frisar que as condições ambientais, tal como apontado ao longo deste trabalho, exercem considerável influência na amamen- tação. Assim, a creche no local de trabalho, ou perto deste, favorece a amamentação. A causa parece ser a proximidade entre mãe e bebê, que permite a essa gerenciar o processo de aleitamento.

No entanto, não basta que mãe e bebê fiquem juntos apenas. É necessário que a creche se organize por meio de condições estruturais e rotinas de acolhimento. A equipe deve estar capacitada acerca do aleitamento materno, especialmente no que diz respeito às questões que surgem nesta fase, como por exemplo, o retorno da nutriz ao trabalho, as mudanças no padrão de aleitamento que ocorrem em consequência do relativo afastamento mãe-bebê, a necessidade de extrair e armazenar seu leite (em casa e/ou na creche) e o modo de administrar este leite ao bebê.

Aliás, no que diz respeito a este tópico, a capacitação de equipes, ressalta-se que também no âmbito da atenção básica à saúde, parceira no processo de incentivo ao aleitamento materno, já foi constatado que esta necessita refletir e aprimorar sua prática ${ }^{21}$. Em pesquisa realizada junto a enfermeiros e médicos lotados em unidades básicas e de saúde da família na cidade de São Carlos (SP) nada foi mencionado a respeito das dificuldades das mães para se adaptarem à transição do bebê do lar à creche, por exemplo. ${ }^{21}$

Quanto às condições estruturais vale lembrar que dificilmente as creches dispõem de uma sala exclusivamente para esse uso. Nossa experiência profissional nos mostra que outros espaços podem ser arranjados de modo que a nutriz tenha privacidade, conforto e, assim, tranquilidade para amamentar. Permitir o uso da própria sala na qual o bebê permanece é uma alternativa que exige boa vontade e disposição, mas que resulta em benefício para a criança, para a mãe, que se tranquiliza ao poder amamentar, e mesmo para a equipe da instituição, quando conscientizada acerca da importância da promoção da amamentação. 
No que tange às rotinas de acolhimento, salienta-se as normas de extração e guarda de leite humano elaboradas pela Fundação Oswaldo Cruz (Fiocruz) ${ }^{10,11}$ e Agência Nacional de Vigilância Sanitária (Anvisa) ${ }^{12}$, que são fáceis de seguir em creches.

Cabe discutir a causa da extração e armazenamento do leite ser pouco praticada. Aspectos relacionados à ordenha do leite, seu armazenamento e administração à criança mostraram constituir o conjunto de temas menos abordados pelas pesquisas, uma vez que a ordenha de leite materno na creche foi o único observado. O próprio fato de tais condições não serem estudadas reforça a sua não-existência. Como não são conhecidas, não são pesquisadas, formando um ciclo vicioso. É possível formular algumas hipóteses para tal: (1) desconhecimento de que é possível extrair e guardar o leite materno em creches; (2) creche e/ou equipe não perceberem que esse é seu papel e acreditarem que cabe à mãe tomar essa iniciativa. Dois trabalhos reforçam esse ponto de vis$\mathrm{ta}^{3,13}$, sendo um deles o mais recente dentre todos os analisados. Neste, os trabalhadores entrevistados verbalizavam claramente essa postura passiva ${ }^{13}$. O de Hardy (1991) o demonstra pela ação inversa, pois descreve o sucesso de um programa de incentivo ao aleitamento materno realizado na Universidade de Campinas (Unicamp), com obtenção de taxas de aleitamento materno mais elevadas do que as da época da pesquisa ${ }^{3}$. As mães, funcionárias e estudantes da instituição, eram contatadas já durante a gestação. Em todas as oportunidades, enfatizava-se a importância da amamentação, como se preparar para ela e como se organizar para o retorno ao trabalho, ocasião em que contariam com apoio da creche da instituição. Desse modo, se evidencia que a creche precisa ter um papel pró-ativo em relação ao tema. Aguardar apenas a iniciativa materna certamente significa insucesso no que diz respeito ao incentivo e suporte para a amamentação.

Vê-se, portanto, que adaptar a creche para efetivamente promover a amamentação é algo viável, e que está de acordo com as iniciativas nacionais adotadas nos últimos anos, tal como o programa "Hospital Amigo da Criança”. Este, lançado no país, em 1990, com incentivo da OMS e do UNICEF, consiste no estímulo à amamentação exclusiva e imediata dos bebês logo após o nascimento, bem como o alojamento conjunto mãe-bebê. A iniciativa foi adotada como ação prioritária no Brasil em $1992^{22}$. Frisa-se, porém, que a amamentação precisa se dar ao longo de dois anos e que as ações iniciadas no hospital e complementadas nas consultas de saúde são insuficientes, motivo que reforça a necessidade do engajamento das creches neste esforço em prol da alimentação dos bebês. Estas precisam ser vistas como instituições onde é possível o desenvolvimento de ações para favorecer o aleitamento materno. Além disto, como o tema está intrinsecamente ligado às condições de trabalho materno estas precisam ser consideradas também. Certamente a confluência desses elementos é que favorecerá a amamentação.

Finalmente percebe-se que o tema amamentação em creche ainda não foi suficientemente explorado e valorizado pelos profissionais de saúde em termos de pesquisa. Assim, seus aspectos são pouco explorados e consequentemente, insuficientemente conhecidos. Este assunto necessita receber maior atenção por parte não só dos pesquisadores, mas também da sociedade como um todo. 


\section{REFERÊNCIAS}

1. Organização Pan-americana da Saúde (OPAS), Organização Mundial da Saúde (OMS). Amamentação. Brasília; 2003 [acesso em 2 ago 2008]. Disponível em: http://www.opas.org.br/sistema/fotos/ amamentar.pdf

2. Segall-Corrêa AM, Marín-León L. Amamentação e alimentação. In: Brasil. Ministério da Saúde. PNDS 2006 Pesquisa nacional de demografia e saúde da criança e da mulher. Brasília: Ministério da Saúde; 2008. p.242-51.

3. Hardy EE, Osis MJ. Mulher, trabalho e amamentação: legislação e prática. Campinas: Unicamp; 1991.

4. Rezende MA. Aleitamento natural numa creche governamental da cidade de São Paulo [dissertação]. São Paulo: Escola de Enfermagem, Universidade de São Paulo; 1992.

5. Fundo das Nações Unidas para a Infância (UNICEF). Situação Mundial da Infância 2008: Caderno Brasil. Brasília: UNICEF; 2008.

6. Brasil. Lei n. 9.394, de 20 de dezembro de 1996. Estabelece as diretrizes e bases da educação nacional. Leis de diretrizes e bases da educação nacional - LDB. Brasília; 1996 [acesso em 18 nov 2008]. Disponível em: http:// www.planalto.gov.br/ccivil_03/LEIS/ 19394.htm.

7. Instituto Brasileiro de Geografia e Estatística (IBGE). Pesquisa mensal de emprego. Algumas características da inserção das mulheres no mercado de trabalho: Recife, Salvador, Belo Horizonte, Rio de Janeiro, São Paulo e Porto Alegre, 2003-2008. Rio de Janeiro: IBGE; 2008.

8. Brasil. Decreto-lei 5.452, de 1 de maio de 1943. Aprova a consolidação das leis do trabalho - CLT. [acesso em 20 nov
2008]. Disponível em: http:// www.planalto.gov.br/ccivil/Decreto-Lei/ Del5452.htm.

9. Brasil. Ministério da saúde. Portaria 321, de 26 de maio de 1988. Aprova as normas e os padrões mínimos, que com esta baixam, destinados a disciplinar a construção, instalação e o funcionamento de creches, em todo o território nacional. [acesso em 2 mar 2009]. Disponível em: http://elegis.bvs.br/leisref/public/ showAct.php?id=671\&word

10. Almeida JAG, Guimarães V, Novak FR. Normas técnicas para bancos de leite humano: coleta. Rio de Janeiro:

FIOCRUZ; 2004. [acesso em 10 ago 2008]. Disponível em: http:// www.bvsam.cict.fiocruz.br/ normastecnicas/coleta.pdf.

11. Almeida JAG, Guimarães V, Novak FR. Normas técnicas para bancos de leite humano: acondicionamento. Rio de Janeiro: Fiocruz; 2004. [acesso em 10 ago 2008]. Disponível em:http:// www.bvsam.icict.fiocruz.br/ normastecnicas/acondicionamento.pdf

12. Brasil. Agência Nacional de Vigilância Sanitária (Anvisa). Banco de leite humano: funcionamento, prevenção e controle de riscos. Brasília: Anvisa; 2008.

13. Maciel AF. Conhecimentos e práticas de trabalhadores de um centro infantil acerca do aleitamento materno [dissertação]. São Paulo: Escola de Enfermagem, Universidade de São Paulo; 2008.

14. Santos-Oliveira NG, Rabinovich EP. Estudo comparativo da amamentação em casas e em creche paulistanas e no interior do Piauí. Rev. Bras. crescimento desenvolv. Hum. 1999;9(1):20-26.

15 Osis MJD, Duarte GA, Pádua KS, Hardy E, Sandoval LEM, Bento SF. Aleitamento materno exclusivo entre trabalhadoras com creche no local de trabalho. Rev Saúde 
Pública [periódico online]. 2004 Abr [citado em 30 set 2007];38(2):172-179. Disponível em: http://www.scielo.br/ scielo.php?script $=$ sci_arttext\&pid=S0034$89102004000200004 \& \operatorname{lng}=p t \& n r m=i s o$.

16. Issler RMS, Enk I, Azeredo PR, Moraes JA. Estudo comparativo do período de aleitamento materno de crianças de creches interna e externa. J. Pediatr. 1994;70(5):287-290.

17. Rea MF, Venâncio SI, Batista LE, Santos

RG, Greiner T. Possibilidades e limitações da amamentação entre mulheres trabalhadoras formais. Rev Saúde Pública [periódico online]. 1997 Abr [acesso em 30 set 2007];31(2):149156. Disponível em: http://

www.scielo.br/ scielo.php?script=sci_arttext\&pid=S003489101997000200008\&lng=pt\&nrm=iso.

18. Spinelli MGN, Sesoko E, Souza JMP, Souza SB. A situação de aleitamento materno de crianças atendidas em creches da Secretaria da Assistência Social do município de São Paulo: região Freguesia do Ó. Rev. Bras. Saúde Mater. Infant. [periódico online]. 2002
Abr [acesso em 23 out 2007]; 2(1):2328. Disponível em: http://www.scielo.br/ scielo.php?script=sci_arttext\&pid=S151938292002000100004\&lng=pt\&nrm=iso.

19. Uchimura TT, Uchimura NS, Furlan J, Oliveira C. Aleitamento materno e alimentação complementar em crianças de duas creches de Maringá-PR. Ciência, Cuidado Saúde. 2003;2(1):25-30.

20. Santos RG. Alimentação de crianças de 6 a 12 meses filhos de mulheres em trabalho formal na Grande São Paulo [dissertação]. São Paulo: Secretaria de Estado da Saúde de São Paulo; 2006.

21. Arantes CIS, Montrone AVG, Milioni DB. Concepções e conhecimento sobre amamentação de profissionais da atenção básica à saúde. Rev. Eletr. Enf. [periódico online]. 2008;10(4):933-44. Disponível em:http://www.fen.ufg.br/ revista/v10/n4/v10n4a06.htm.

22. Brasil. Fundo para as Nações Unidas para a Infância (UNICEF). Iniciativa Hospital Amigo da Criança [homepage online]. [acesso em 13 abr 2009]. Disponível em: http://www.unicef.org/ brazil/pt/activities_9994.htm.

Recebido em 28 de março de 2009. Modificado em 12 de julho de 2009. Aceito em 26 de setembro de 2009. 